\title{
Impact of percutaneous embolization versus subinguinal microsurgical ligation on semen parameters in primary varicocele patients: comparative study
}

\author{
Haytham M. Nasser ${ }^{1}$, Ahmed Hussein ${ }^{1 *}$, Gad M. Behairy ${ }^{2}$ and Mostafa Abdo²
}

\begin{abstract}
Background: Varicocele is an abnormally dilated pampiniform plexus of the veins within the spermatic cord and is considered the most common correctable cause of male factor infertility. Many approaches are described for treatment either surgical (tradition inguinal, subinguinal, and laparoscopic) or non-surgical percutaneous embolization. During the period from August 2017 to December 2018, we prospectively analyzed the preoperative and post-operative alteration of semen parameters (at 3 and 9 months) of the data collected from 63 patients with clinically evident varicocele referred to our tertiary hospital. Patients were divided into two groups: group 1, thirtythree patients who underwent subinguinal microsurgical ligation, and group 2, thirty patients who underwent percutaneous embolization.
\end{abstract}

Results: Sixty-three patients enrolled in this study were divided in two groups: group 1, patients who underwent surgery, and group 2, patients who underwent embolization; the mean age is $24.6 \pm 1.27$ years in group 1 and 23.7 \pm 2 years in group 2; there was no statistically significant difference between the two groups as regards BMl, diabetes, hypertension, and smoking. Bilaterality was present in 15.2\% of group 1 patients and $10 \%$ in group 2 patients ( $P$ value 0.06). Most of the patients were classified as grades 2 and 3 with no statistical significance regarding severity of the disease. Preoperative semen parameters for patients including sperm count, motility, and abnormal forms showed no statistically significant difference between the two groups. Post-intervention semen analysis was done twice during follow-up after 3 months and 9 months from the date of intervention. After 3 months, the semen parameters were improved in both groups in spite of the higher sperm count in group 2 but with no statistical significance. After 9 months follow-up, semen analysis showed persistent increase in sperm mobility in group 1 patients in comparison to group 2 patients. Both groups had better improvement in count of normal form with no statistical significant change.

Conclusion: Improvement of semen parameters while treating primary varicocele by either subinguinal microsurgery approach or percutaneous embolization shows equivalent outcomes.

Keywords: Varicocele, Percutaneous embolization, Subinguinal microsurgical ligation

\footnotetext{
* Correspondence: ahmed_hussein99@yahoo.com

'Department of Radiology, Faculty of Medicine, Ain Shams University, Cairo,

Egypt

Full list of author information is available at the end of the article
}

\section{Springer Open}

( ) The Author(s). 2020 Open Access This article is licensed under a Creative Commons Attribution 4.0 International License, which permits use, sharing, adaptation, distribution and reproduction in any medium or format, as long as you give appropriate credit to the original author(s) and the source, provide a link to the Creative Commons licence, and indicate if changes were made. The images or other third party material in this article are included in the article's Creative Commons licence, unless indicated otherwise in a credit line to the material. If material is not included in the article's Creative Commons licence and your intended use is not permitted by statutory regulation or exceeds the permitted use, you will need to obtain permission directly from the copyright holder. To view a copy of this licence, visit http://creativecommons.org/licenses/by/4.0/. 


\section{Background}

Varicocele is defined as tortuous abnormally dilated pampiniform plexus of the veins within the spermatic cord [1].

Varicocele is prevalent, occurring in approximately $15 \%$ of all men, $35 \%$ of men with primary infertility, and up to $80 \%$ of men with secondary infertility. Although most of the patients are asymptomatic, there is a clear association between varicocele and progressive decline in testicular function resulting in impaired semen parameters and possibly decreased serum testosterone [2].

It is likely to be multifactorial. Recent studies showed that it resulted mainly in higher levels of reactive oxygen species (ROS) [3]. The ROS rise causes fragmentation of the sperm DNA, which in turn causes decline in the sperm function and fertilization outcome [4].

Accordingly, treatment of varicocele has been shown to arrest continued decline in testicular function and improve semen parameters and, in some reports, serum testosterone [5].

Treatment of varicocele in patients with primary or secondary infertility may help in avoiding the need for assisted reproduction or any further intervention, cost, and psychological stress [2].

Many approaches have been described for varicocele treatment either surgical or non-surgical (radiological). Surgical approaches starting with conventional inguinal and subinguinal is done through inguinal incision and ligation of all dilated spermatic veins with caution to avoid ligation of the spermatic artery. Down to the less invasive surgical technique where ligation of the internal spermatic veins proximally is done laparoscopically [2].

Radiographic approaches have the privileges of doing venography and identify the internal spermatic and collateral veins with subsequent embolization [2].

Percutaneous embolization is the least invasive and does not need surgical incisions, so it can be performed under local anesthesia, whereas surgical approaches require more complicated anesthetic procedures [2].

The use of venography is characterized by identification of both internal spermatic vein and any collateral which may contribute in the pathology and may cause surgical failure or recurrence later on [6].

In addition, the percutaneous embolization method eliminates the potential risk for damaging the testicular artery, which in turn decrease complications related to testicular pain and atrophy [2].

\section{Aim of the work}

The aim of this study is to compare the effect of both therapeutic techniques, percutaneous embolization, and subinguinal microsurgical ligation in improving the semen parameters (count, motility, and normal forms) in patients with primary varicocele.

\section{Study design}

This study is a non-randomized control study.

\section{Methods}

During the period from August 2017 to December 2018, we prospectively analyzed preoperative and postoperative alteration of semen parameters (at 3 and 9 months) of 63 patients with clinically evident varicocele referred to our tertiary hospital.

Patients were divided into two groups: group 1, thirtythree patients who underwent subinguinal microsurgical ligation, and group 2, thirty patients who underwent percutaneous embolization.

Patients with unilateral or bilateral varicocele diagnosed clinically and confirmed by U/S (GE logiq P5) with abnormal semen parameters (count, motility, and abnormal forms) were included, while patients with recurrent varicocele or azoospermia, bleeding tendency, and any contraindication to the injection of contrast such as high serum creatinine or allergy were excluded as well, as well as patients with sperm count less than 1 million, as they need further investigations with karyotyping.

All cases were evaluated in the andrology clinic and referred for intervention after patient counseling. The choice of the technique was taken by the patients themselves after discussing the advantages and the disadvantages of each procedure without any financial issue for both procedures.

Pre-operative assessment included complete detailed history, physical examination, scrotal ultrasound, and Doppler and semen analysis.

Doppler US was done by the same expert radiologist with complete comment on the testis as regards the size, echogenicity, and vascularity and the pampiniform plexus of veins as regards the diameter and flow direction with and without Valsalva maneuver (Fig. 1).

Correlation between clinical examination and scrotal Doppler was done with grading of the varicocele into subclinical, grade I, grade II, and grade III according to the Dubin grading system [7].

Semen analysis was performed preoperative and postoperative at 3 and 9 months, patients were advised to do it after abstinence of at least 7 days, all samples were sent to the hospital laboratory, and data about volume, count, motility, and normal forms were recorded.

\section{Interventional technique}

\section{Percutaneous embolization}

The procedure was done under local anesthesia using Siemens axiom artis cath/angio system. Vascular access was done via the right internal jugular vein which is preferred for early patient ambulation. U/S-guided vascular access was done using a 16-G puncture needle. A Terumo guide wire $\left(0.035^{\prime \prime}\right)$ (Terumo, Japan) was introduced 


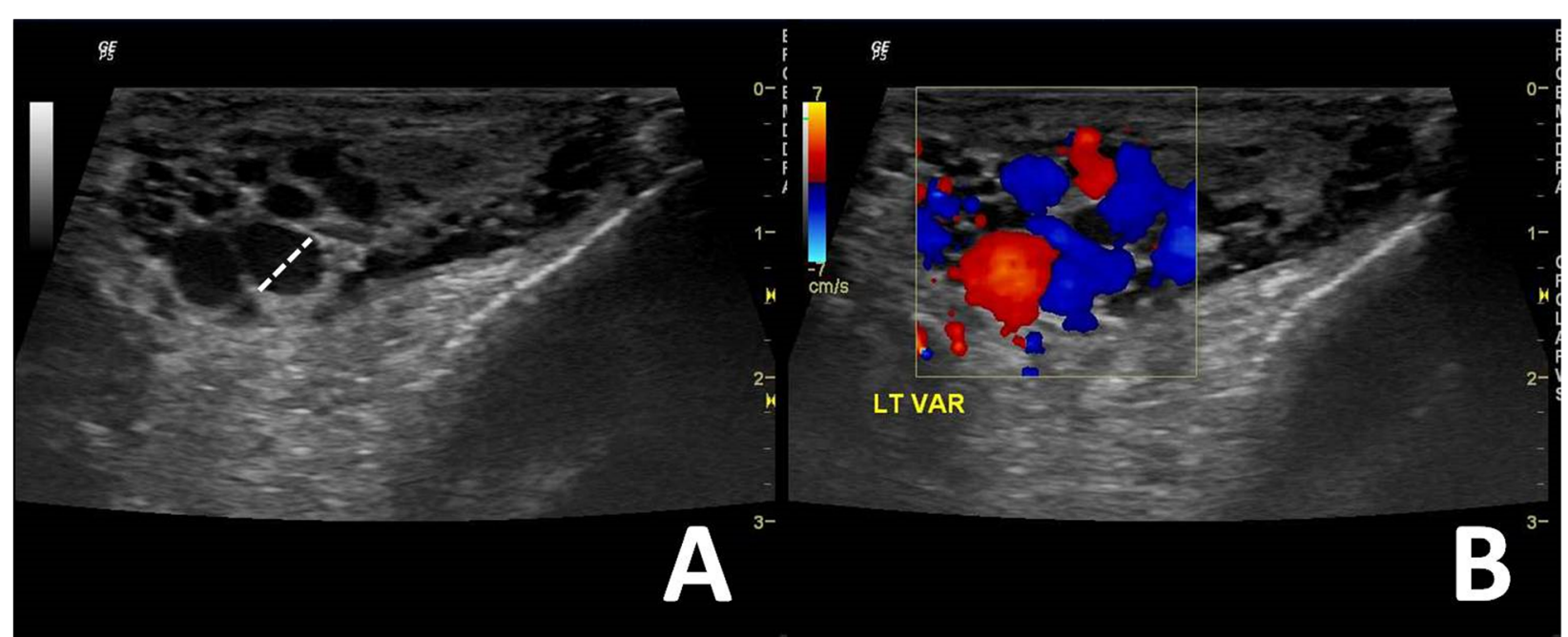

Fig. 1 Grayscale B mode scrotal ultrasound demonstrating multiple dilated pampiniform plexus veins reaching $6 \mathrm{~mm}$ (a). Color duplex examination shows accentuation of blood flow with reflux on the Valsalva maneuver (b)

through needle to the internal jugular vein (IJV) down to the subclavian vein (SCV) crossing the right atrium down to the inferior vena cava (IVC). Vascular sheath was applied, a 4-F vertebral catheter (Boston Scientific, USA) was introduced over the wire, the wire was withdrawn, and the catheter was manipulated under fluoroscopic guidance where the spermatic vein was identified from the IVC on the right side and from the left renal vein on the left side.

The catheter was introduced till the pelvic inlet midinguinal point just above the scrotal neck. Spermatic vein venography was done to ensure the diagnosis, where the venography was positive if the contrast reflux to the pampiniform plexus of vein (sometimes Valsalva was needed to confirm diagnosis).

Catheterization of the spermatic vein was done followed by complete embolization using histoacryl (B. Braun, German) lipiodol emulsion (Guerbet, USA) with the ratio 2 lipiodol to 1 histoacryl (Fig. 2).

The histoacryl lipiodol emulsion was injected slowly with catheter pullback technique together with external inguinal compression to avoid the escape of emulsion into the scrotal sac and Valsalva to avoid the escape of the emulsion into the renal vein (Fig. 3).

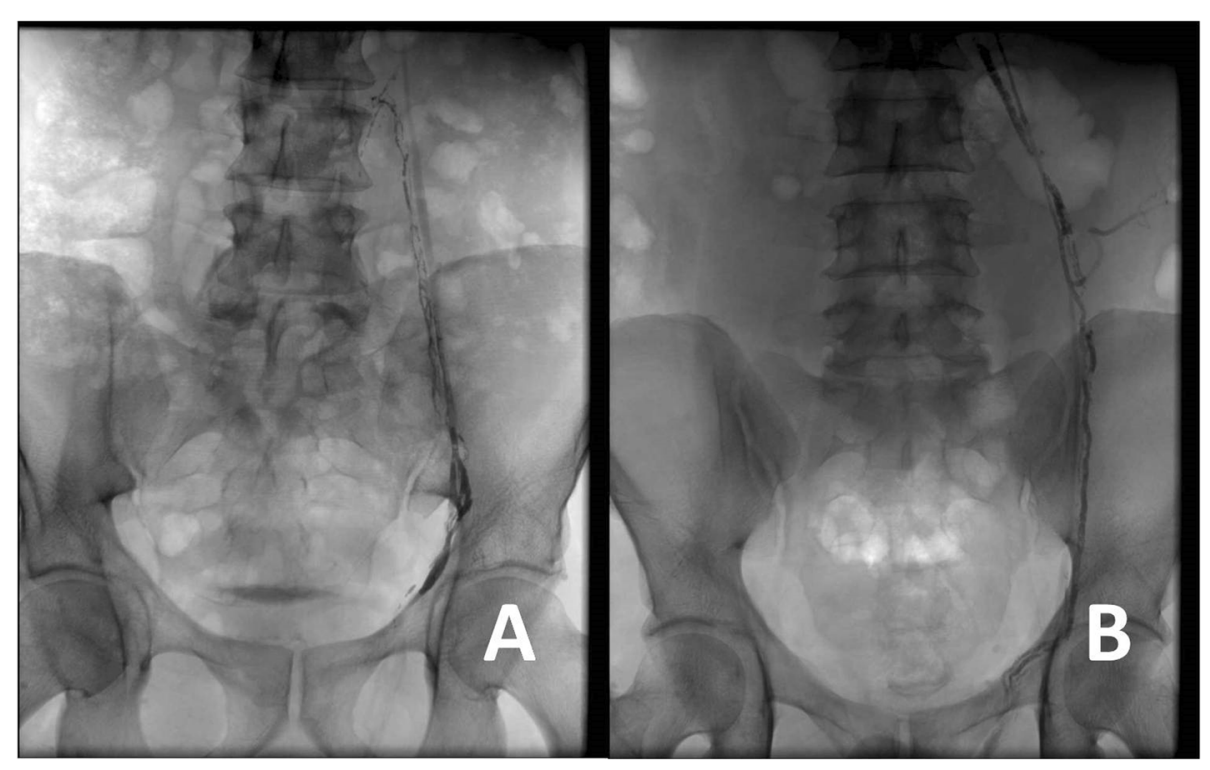

Fig. 2 Left varicocele embolization with histoacryl. Histoacryl injection is done during the Valsalva maneuver with external compression. Multiple collateral channels are shown, with filling of collateral channels with histoacryl/lipiodol as the catheter was withdrawn $(\mathbf{a}, \mathbf{b})$ 


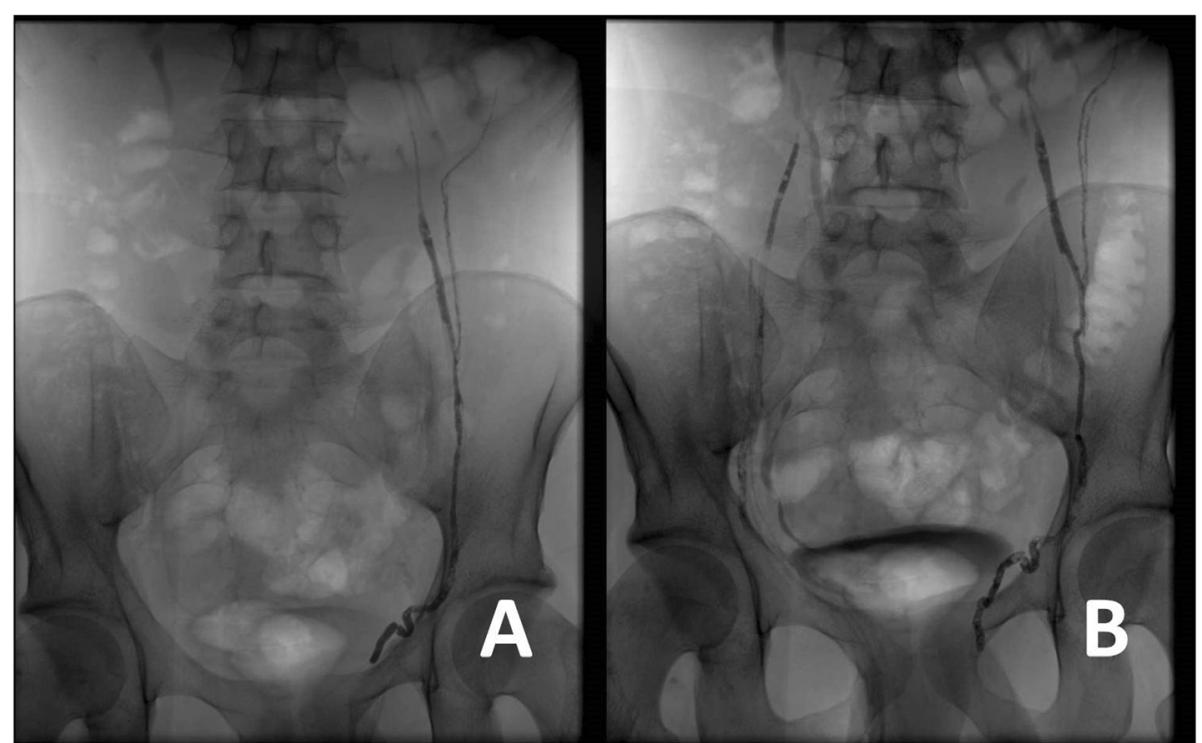

Fig. 3 Bilateral varicocele embolization with histoacryl. First, we started by the lest side (a) which has higher grade on Doppler US. Then, right embolization is done (b)

\section{Subinguinal microsurgical approach}

After sterilization, a 3-cm transverse subinguinal incision was done (the approach was done without delivery of the testis). Using surgical loups with a magnification power of 4.5 times, external spermatic fascia was opened and the spermatic cord structures were retracted, and then identification of all spermatic cord veins was done followed by double ligation using 3-0 vicryl sutures (Fig. 4) after preservation of the arteries (confirmed by feeling arterial pulsations) and lymphatic channels. Closure of the subcutaneous tissue using interrupted sutures 3-0 vicryl was done, and the skin was closed using 4-0 undyed vicryl sutures.

\section{Ethical consideration}

An informed consent was obtained from the patient concerning the complication of the procedure, the complication of the glue, and the acceptance to be enrolled in the study.

\section{Statistical analysis}

Data were coded and entered using the statistical package SPSS (Statistical Package for the Social Sciences) version 23. Data were summarized using mean, standard deviation, median, minimum, and maximum in quantitative data and using frequency (count) and relative frequency (percentage) for categorical data. Comparisons
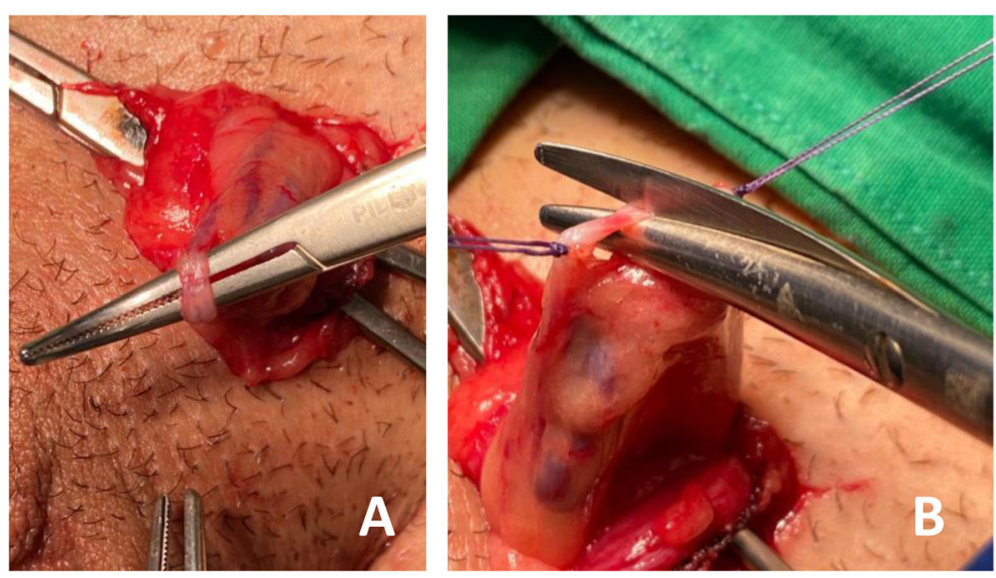

Fig. 4 During subinguinal microsurgical approach, a selective identification of all spermatic cord veins followed by b double ligation using 3-0 vicryl sutures 
Table 1 Baseline characteristics of the patients

\begin{tabular}{llll}
\hline Characteristics & Group 1 & Group 2 & P value \\
\hline Age, range (mean \pm SD) & $18-36(24.6 \pm 1.27)$ & $\mathbf{N = 3 0}$ & 0.26 \\
BMI, range (mean \pm SD) & $19-31(27.54 \pm 4.25)$ & $18-38(23.7 \pm 2)$ & $18-29(25.93 \pm 3.89)$ \\
DM, $n(\%)$ & $1(3 \%)$ & $2(6 \%)$ & 0.17 \\
HTN, $n(\%)$ & $3(9 \%)$ & $2(6 \%)$ & 0.09 \\
Smoking, $n(\%)$ & $11(33 \%)$ & $12(40 \%)$ & 0.34 \\
Side affected & & & 0.22 \\
$\quad$ Left side, $n(\%)$ & $28(84.8 \%)$ & $27(90 \%)$ & 0.48 \\
$\quad$ Bilateral, $n(\%)$ & $5(15.2 \%)$ & $3(10 \%)$ & 0.06
\end{tabular}

between quantitative variables were done using chisquared test and paired $t$ test. $P$ value less than or equal 0.05 was considered statistically significant.

\section{Results}

The 63 patients enrolled in this study were divided in two groups according to the technique of intervention: group 1, patients who underwent surgery, and group 2, patients who underwent embolization; the mean age is $24.6 \pm 1.27$ years in group 1 and $23.7 \pm 2$ years in group 2 ; there was no statistically significant difference between the two groups as regards BMI, diabetes, hypertension, and smoking as shown in Table 1.

Bilaterality was present in $15.2 \%$ of group 1 patients and $10 \%$ in group 2 patients (Table 1) with no statistical significant difference between the two groups ( $P$ value 0.06). As shown in Table 2, most of the patients were classified as grades 2 and 3 with scrotal Doppler; again, no statistical significance was present between the two groups regarding the severity of the disease.

Preoperative semen (Table 3) parameters for patients in the two groups including sperm count, motility, and abnormal forms were compared which showed no statistically significant difference between the two groups. Post-intervention, the semen analysis was done twice during the follow-up after 3 months and 9 months from the date of intervention.

After 3 months, the semen parameters (Table 4) were improved in both groups, but neither of them succeeded to show any statistical significance over the other in

Table 2 Scrotal ultrasound and Doppler

\begin{tabular}{llll}
\hline Characteristics & $\begin{array}{l}\text { Group 1 } \\
\mathbf{N = 3 3}\end{array}$ & $\begin{array}{l}\text { Group 2 } \\
\mathbf{N = 3 0}\end{array}$ & $\boldsymbol{P}$ value \\
\hline Grade 1, $n$ & 1 & 1 & 0.2 \\
Grade 2, $n$ & 12 & 9 & 0.08 \\
Grade 3, $n$ & 15 & 14 & 0.43 \\
Grade $4, n$ & 5 & 6 & 0.34 \\
\hline
\end{tabular}

spite of the higher sperm count in group 2 but with no significance (Fig. 5).

After 9 months, the follow-up semen analysis showed a persistent increase in sperm mobility in group 1 patients in comparison to group 2 patients (Fig. 5). Both groups had a better improvement in the count of normal form with no statistical significant change seen when comparing these parameters in both groups (Table 5).

\section{Discussion}

A study done by Shiraishi et al. [8] compared the different surgical techniques of varicocelectomy including subinguinal microsurgical, high inguinal, and retroperitoneal approaches as regards the results and complication and revealed a faster and higher sperm concentration and motility after the use of the microsurgical approaches. A meta-analysis of randomized clinical trials done by Kim et al. [9] recommended subinguinal microsurgical approach as a first-line treatment of subfertile men with impaired semen quality.

Therefore, we conducted the same approach in our study especially that it allows the lowest recurrence rate (0.8 to $4 \%$ ), without exposing to severe complications [10].

However, data concerning the percutaneous embolization remain scarce. A recent radiological study done by Cassidy et al. [11] concluded that embolization is similar to surgery and had to be a new gold standard except in case of bilateral varicocele.

In this study, both groups showed a significant improvement in sperm count, sperm motility, and normal

Table 3 Preoperative semen parameters

\begin{tabular}{llll}
\hline Characteristics & $\begin{array}{l}\text { Group } \mathbf{1} \\
\mathbf{N = 3 3}\end{array}$ & $\begin{array}{l}\text { Group 2 } \\
\mathbf{N = 3 0}\end{array}$ & P value \\
\hline Sperm count $\times 10^{6} / \mathrm{ml}$ & $7.44 \pm 0.32$ & $\begin{array}{l}10.32 \pm 0.59 \\
\text { (mean } \pm \text { SD) }\end{array}$ & 0.08 \\
Sperm motility (mean \pm SD) & $26.8-8.08$ & $9.21-11.43$ & \\
& $25.13-28.63$ & $26.89-29.03$ & \\
Normal forms (mean \pm SD) & $7.68 \pm 0.49$ & $5.16 \pm 0.37$ & 0.19 \\
& $6.7-8.66$ & $4.34-5.98$ & \\
\hline
\end{tabular}


Table 4 Semen parameters after 3 months

\begin{tabular}{|c|c|c|c|}
\hline Characteristics & $\begin{array}{l}\text { Group } 1 \\
N=33\end{array}$ & $\begin{array}{l}\text { Group } 2 \\
N=30\end{array}$ & $P$ value \\
\hline Sperm count $\times 10^{6} / \mathrm{ml}($ mean \pm SD $)$ & $\begin{array}{l}9.72 \pm 0.28 \\
9.2-10.24\end{array}$ & $\begin{array}{l}16.08 \pm 0.65 \\
15.17-16.99\end{array}$ & 0.05 \\
\hline Sperm motility (mean \pm SD) & $\begin{array}{l}32.64 \pm 0.70 \\
31.39-33.89\end{array}$ & $\begin{array}{l}33.12 \pm 0.65 \\
32.18-34.06\end{array}$ & 0.32 \\
\hline Normal forms (mean \pm SD) & $\begin{array}{l}7.56 \pm 0.26 \\
7.12-8\end{array}$ & $\begin{array}{l}5.88 \pm 0.43 \\
5.24-6.52\end{array}$ & 0.28 \\
\hline
\end{tabular}

forms at 3 and 9 months post-operatively. There was no significant difference according to postoperative semen parameters between the two groups, except a higher sperm count at 3 months postoperatively in group 2 . This can be explained by the preoperative tendency for higher sperm count concentration in group $2(10.32 \times$ $106 / \mathrm{ml}$ vs. $7.44 \times 106 / \mathrm{ml}$ in group 1 ). Our results go with that of Bou Nasr et al. [12] that both techniques improve the semen parameters in the same pattern.

As regards group 1 following surgical correction, we observed a stable increase in the semen quality reaching maximum by the third month then entering a plateau. In comparison, in the patients in group 2 subjected to embolization, the sperm count declined back after initial increase at the third month, but sperm motility and normal forms showed a nearly similar pattern of improvement as group 1. It is worth mentioning that semen quality improvement remains higher preoperatively. The study done by Bou Nasr et al. [12] observed a sharper rebound at 3 months in all parameters. Similarly, Al Bakri et al. [13] reported that sperm parameters improved by 3 months, and then no more improvement by 6 months or longer, and he cannot attribute this phenomenon to a clear cause.

Fortunately, in our study, we did not face any cases of technical failure in the embolization group. The overall failure rate of $3.2 \%$ for left-sided embolization was reported by Cassidy et al. [11], while the overall technical failure rate for varicocele embolization in published meta-analysis was $13.05 \%$ [14]. Our data appear to be due to the small number of patients with only three patients with bilateral varicocele.
Here, it is worth mentioning that in the series published by Cassidy et al. [11], the high technical failure rate with right-sided embolization attempts was $19 \%$, and he believes that men with bilateral varicocele and male factor infertility are best managed with surgical varicocele repair, as the failure rates are equal from the left side to the right side at nearly $3 \%$.

The same concept was conducted by Halpern et al. [2] that due to significant high technical failure rates for right-sided varicocele and the likelihood to require further surgical therapy, bilateral grade 3 varicocele should not be considered for embolization. Obviously, the number of bilateral cases in our study is too low to draw any meaningful conclusions.

Multiple embolic materials either solid as coils or fluid as histoacryl may be used in embolization. In our study, we used histoacryl based on our experience and previously reported fact in literature considering the recurrence rate $[15,16]$, where the mechanism of action in solid embolic agents such as coils is local at the site of embolization representing more or less equivalent solution to the surgical option, which are not that effective in the presence of collateral and, in turn, may be a leading cause of recurrence. Other studies recommended the combined use of both coils and histoacryl and used the name of sandwich technique [17]. This decreases the risk of histoacryl migration decreasing the rate of complication yet still carries financial issue as regards the cost, where Jargiello et al. used combined solid (coils) and liquid embolic material with the lowest relapse rate reported in the literature 0\% [18]. Yet, Puche-Sanz et al.

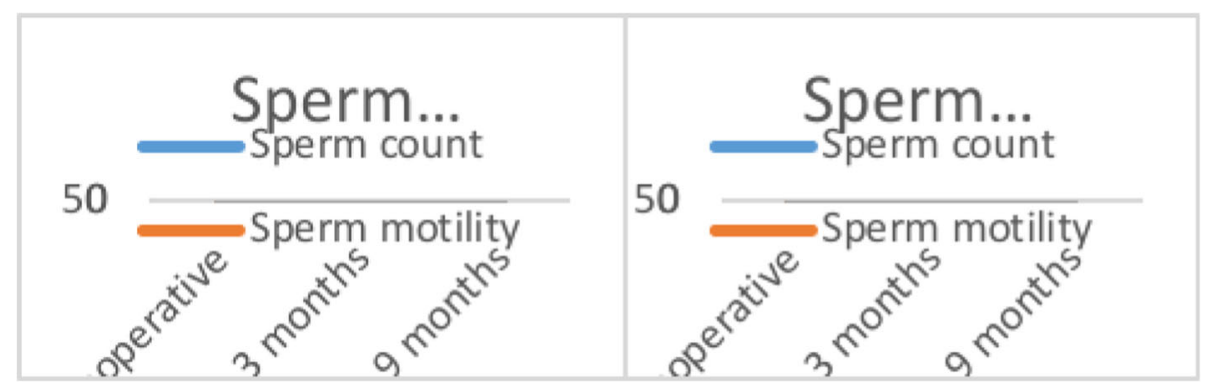

Fig. 5 A line chart showing the changes in the semen parameter in both group through the follow-up period 
Table 5 Semen parameters after 9 months

\begin{tabular}{|c|c|c|c|}
\hline Characteristics & $\begin{array}{l}\text { Group } 1 \\
N=33\end{array}$ & $\begin{array}{l}\text { Group } 2 \\
N=30\end{array}$ & $P$ value \\
\hline Sperm count $\times 10^{6} / \mathrm{ml}($ mean \pm SD) & $\begin{array}{l}13.44 \pm 0.52 \\
12.42-14.46\end{array}$ & $\begin{array}{l}17.16 \pm 0.67 \\
16.1-18.22\end{array}$ & 0.09 \\
\hline Sperm motility, \% (mean \pm SD) & $\begin{array}{l}31.92 \pm 0.58 \\
30.97-32.87\end{array}$ & $\begin{array}{l}28.80 \pm 1.35 \\
27.14-30.46\end{array}$ & 0.14 \\
\hline Normal forms, \% (mean \pm SD) & $\begin{array}{l}13.08 \pm 0.54 \\
12.19-13.97\end{array}$ & $\begin{array}{l}12.96 \pm 0.47 \\
12.18-13.74\end{array}$ & 0.43 \\
\hline
\end{tabular}

used coils alone with the highest relapse rate reported in study $13.1 \%$ [19].

However, a few limitations must be mentioned when analyzing our results, mainly the small sample size, the absence of randomization, and the inability to verify recurrence and birth rate.

\section{Conclusion}

The improvement of semen parameters while treating primary varicocele, by either subinguinal microsurgery approach or percutaneous embolization, shows equivalent outcomes. We cannot go into recommendations because of the various limitations of the current study especially the small sample size, but we feel free choosing both options according to availability and patient preferences.

\section{Abbreviations}

US: Ultrasound; BMI: Body mass index; ROS: Reactive oxygen species;

SCV: Subclavian vein; IVC: Inferior vena cava

\section{Acknowledgements}

Not applicable.

\section{Authors' contributions}

All authors have read and approved the manuscript. $\mathrm{AH}$, the corresponding author, contributed by doing the study concept and design. Also, patient recruitment, follow-up, and acquisition of data were done by HM. Procedures were done by $\mathrm{HM}, \mathrm{MA}$, and $\mathrm{AH}$. Analysis and interpretation of data and the drafting of the manuscript were done by HM. Revision of the manuscript was by $H M, G M$, and $A H$. Technical or material support was done by $H M, A H$, and $\mathrm{AA}$.

\section{Funding}

This study did not receive funding, sponsorship, or financial support to be disclosed.

\section{Availability of data and materials}

All data generated or analyzed during this study are included in this published article and are available from the corresponding author.

\section{Ethics approval and consent to participate}

This study was approved by the Research Ethics Committee of the Faculty of Medicine at Ain Shams University in Egypt.

The reference number of approvals is not applicable.

All patients included in this study gave written informed consent to participate in this work.

\section{Consent for publication}

All the patients in the study gave written informed consent for catheterization and for the possibility to publish the data within this research publication.
Competing interests

All the authors declare that they have no competing interest.

\section{Author details}

${ }^{1}$ Department of Radiology, Faculty of Medicine, Ain Shams University, Cairo, Egypt. ${ }^{2}$ Department of General Surgery, Faculty of Medicine, Ain Shams University, Cairo, Egypt.

Received: 5 September 2020 Accepted: 24 November 2020

Published online: 05 December 2020

\section{References}

1. Wein AJ, Kavoussi LR, Novick AC, Partin AW, Peters CA (2011) CampbellWalsh urology: expert consult premium edition: enhanced online features and print, 4-volume set. USA: Elsevier Health Sciences

2. Halpern J, Mittal S, Pereira K, Bhatia S, Ramasamy R (2016) Percutaneous embolization of varicocele: technique, indications, relative contraindications, and complications. Asian J Androl 18(2):234

3. Zini A, Azhar R, Baazeem A, Gabriel M (2011) Effect of microsurgical varicocelectomy on human sperm chromatin and DNA integrity: a prospective trial. Int J Androl 34(1):14-19

4. Ding G-L, Liu Y, Liu M-E, Pan J-X, Guo M-X, Sheng J-Z, Huang H-F (2015) The effects of diabetes on male fertility and epigenetic regulation during spermatogenesis. Asian J Androl 17(6):948

5. Tanrikut C, McQuaid JW, Goldstein M (2011) The impact of varicocele and varicocele repair on serum testosterone. Curr Opin Obstet Gynecol 23(4): 227-231

6. Moon KH, Cho SJ, Kim KS, Park S, Park S (2012) Recurrent varicoceles: causes and treatment using angiography and magnification assisted subinguinal varicocelectomy. Yonsei Med J 53(4):723-728

7. Dubin L, Amelar RD (1970) Varicocele size and results of varicocelectomy in selected subfertile men with varicocele. Fertil Steril 21(8):606-609

8. Shiraishi K, Oka S, Ito H, Matsuyama H (2012) Comparison of the results and complications of retroperitoneal, microsurgical subinguinal, and high inguinal approaches in the treatment of varicoceles. J Androl 33(6):13871393

9. Kim KH, Lee JY, Kang DH, Lee H, Seo JT, Cho KS (2013) Impact of surgical varicocele repair on pregnancy rate in subfertile men with clinical varicocele and impaired semen quality: a meta-analysis of randomized clinical trials. Korean J Urol 54(10):703-709

10. Wang J, Xia S-J, Liu Z-H, Tao L, Ge J-F, Xu C-M, Qiu J-X (2015) Inguinal and subinguinal micro-varicocelectomy, the optimal surgical management of varicocele: a meta-analysis. Asian J Androl 17(1):74

11. Cassidy D, Jarvi K, Grober E, Lo K (2012) Varicocele surgery or embolization: which is better? Can Urol Assoc J 6(4):266

12. Nasr EB, Binhazzaa M, Almont T, Rischmann P, Soulie M, Huyghe E (2017) Subinguinal microsurgical varicocelectomy vs. percutaneous embolization in infertile men: prospective comparison of reproductive and functional outcomes. Basic Clin Androl 27(1):11

13. Al Bakri A, Lo K, Grober E, Cassidy D, Cardoso JP, Jarvi K (2012) Time for improvement in semen parameters after varicocelectomy. J Urol 187(1):227231

14. Cayan S, Shavakhabov S, Kadioğlu A (2009) Treatment of palpable varicocele in infertile men: a meta-analysis to define the best technique. J Androl 30(1):33-40

15. Favard N, Moulin M, Fauque P, Bertaut A, Favelier S, Estivalet L, Michel F, Cormier L, Sagot P, Loffroy R (2015) Comparison of three different embolic 
materials for varicocele embolization: retrospective study of tolerance, radiation and recurrence rate. Quant Imaging Med Surg 5(6):806

16. Sze DY, Kao JS, Frisoli JK, McCallum SW, Kennedy WA II, Razavi MK (2008) Persistent and recurrent postsurgical varicoceles: venographic anatomy and treatment with $\mathrm{N}$-butyl cyanoacrylate embolization. J Vasc Interv Radiol 19(4):539-545

17. Siegel D (2014) Imaging and interventional therapy for varicoceles. Curr Urol Rep 15(4):399

18. Jargiello T, Drelich-Zbroja A, Falkowski A, Sojka M, Pyra K, SzczerboTrojanowska M (2015) Endovascular transcatheter embolization of recurrent postsurgical varicocele: anatomic reasons for surgical failure. Acta Radiol 56(1):63-69

19. Puche-Sanz I, Flores-Martín J, Vázquez-Alonso F, Pardo-Moreno P, Cózar-Olmo J (2014) Primary treatment of painful varicocoele through percutaneous retrograde embolization with fibred coils. Andrology 2(5):716-720

\section{Publisher's Note}

Springer Nature remains neutral with regard to jurisdictional claims in published maps and institutional affiliations.

\section{Submit your manuscript to a SpringerOpen ${ }^{\circ}$ journal and benefit from:}

- Convenient online submission

- Rigorous peer review

- Open access: articles freely available online

- High visibility within the field

- Retaining the copyright to your article

Submit your next manuscript at $\boldsymbol{\nabla}$ springeropen.com 